\title{
Pengaruh Metode Pembelajaran Dan Kepribadian Terhadap Keterampilan Berbicara Bahasa Inggris Siswa SMA Negeri di Cibinong
}

\author{
Rizky Mirani \\ ABA Bina Sarana Informatika Jakarta \\ Jl. Salemba Tengah No. 45 Jakarta Pusat \\ Email: rizky.rrr@bsi.ac.id
}

\begin{abstract}
The purpose of this study was to determine the interactive effect of grammar mastery and motivation trait towards descriptive English writing skill. Sample size is 80 students, and the sampling technique is simple random sampling. Research instruments used were the test results of motivation trait and descriptive English writing skill scoring that have been tested regression coefficient value of 0,008 and 1,738. The used test is multiple regression analysis. Research instrument used is a questionnaire about the personality of students who have tested its validity with the reliability coefficient of 0.875 and the speaking skills test. Data analysis using descriptive statistical method, normality test, homogeneity test and two way ANOVA. The results showed: 1) There are significant interactive effects of methodolo and motivation trait towards descriptive English writing skill as Fobserved = 29,981 > Ftable 2,72 at the 5\% significance level. 2) There is a significant effect of grammar mastery towards descriptive English writing skill, as tobserved $=4,000>$ ttable $=1,684$ at the 5\% significance level. 2) There is a significant effect of motivation trait towards descriptive English writing skill as tobserved = 7,703 $>$ ttable = 1,671 at the 5\% significance level. The results contribute most to the increasing of descriptive English writing skill by grammar mastering and increasing the motivation.
\end{abstract}

Keywords: Grammar Mastery, Motivation, Speaking Skill

\section{PENDAHULUAN}

Bahasa memiliki peran penting dalam perkembangan intelektual, sosial, dan emosional siswa untuk menunjang keberhasilan dalam proses pembelajaran. Pembelajaran bahasa diharapkan dapat membantu para siswa untuk menyatakan pendapat dan perasaan serta berkomunikasi dalam masyarakat yang menggunakan bahasa tersebut.

Bahasa digunakan untuk mengembangkan pengetahuan agar siswa dapat mengekspresikan ide mereka. Finnochiaro (1997:8) mengatakan bahwa "Language is a system of arbitrary vocal symbols which permit all people in a given culture or other people who have learned the system of culture, to communicate, or to interact."

Bahasa Inggris merupakan salah satu bahasa terbesar di dunia yang dipakai sebagai bahasa komunikasi baik lisan maupun tertulis. Di era globalisasi, kedudukan bahasa Inggris semakin menguat, karena bahasa tersebut dipakai di dalam semua bidang, seperti ilmu pengetahuan, teknologi, komunikasi, politik, ekonomi, perdagangan, perbankan, budaya, seni, dan film.

Bahasa Inggris telah diajarkan di SMA sebagai pelajaran wajib. Dalam pembelajaran bahasa Inggris, ada empat keterampilan bahasa yang diajarkan, yaitu mendengarkan, berbicara, membaca, dan menulis. Dari empat keterampilan berbahasa, penulis hanya berkonsentrasi pada keterampilan berbicara.

Berbicara merupakan salah satu aspek keterampilan berbahasa yang bersifat produktif. Artinya, suatu kemampuan yang dimiliki seseorang untuk menyampaikan gagasan, pikiran atau perasaan sehingga gagasan-gagasan yang ada dalam pikiran pembicara dapat dipahami orang lain. Berbicara berarti mengemukakan ide atau pesan lisan secara aktif melalui lambang-lambang bunyi agar terjadi kegiatan komunikasi antara penutur dan mitra tutur. Memang setiap orang dikodratkan untuk bisa berbicara atau berkomunikasi secara lisan, tetapi tidak semua memiliki keterampilan untuk berbicara secara baik dan benar. Berbicara diartikan sebagai kemampuan mengucapkan bunyi-bunyi artikulasi atau kata-kata untuk mengekspresikan, menyatakan dan menyampaikan pikiran, gagasan, serta perasaan. (Tarigan, 1983:14).

Biasanya siswa lancar berkomunikasi dalam situasi tidak resmi atau di luar sekolah, tetapi ketika mereka diminta berbicara di depan kelas, siswa mengalami penurunan kelancaran berkomunikasi. Djago, dalam Tarigan (1992:143), berpendapat bahwa ada sejumlah siswa yang masih merasa takut berdiri di hadapan teman sekelasnya. Bahkan tidak jarang terlihat beberapa siswa berkeringat dingin, berdiri kaku dan lupa apa yang akan dikatakan apabila ia berhadapan 
dengan sejumlah siswa lainnya. Siswa yang belum lancar berbicara tersebut terkadang bersikap pasif, malas berbicara, takut salah dan malu, atau kurang berminat untuk berlatih berbicara di depan kelas. Hal ini juga berkaitan dengan kepribadian yang dimiliki oleh siswa. Siswa yang berkepribadian introvert cenderung diam dan kurang berminat untuk berbicara di depan kelas. Siswa berkepribadian introvert biasanya tidak pandai berkomunikasi. Mereka cenderung tertutup dan tidak suka jadi pusat perhatian, sedangkan siswa yang berkepribadian ekstrovert cenderung lebih mudah dalam berkomunikasi dengan dunia sekitarnya.

Pendekatan dan metode pembelajaran yang dilakukan guru juga berpengaruh terhadap penerimaan murid akan materi yang disampaikan. Kesesuaian kondisi, baik fasilitas, kondisi psikologis, (aspek afektif, kognitif, dan psikomotorik) serta lingkungan murid yang bersangkutan dengan pendekatan dan metode pembelajaran yang dilakukan oleh seorang guru akan membuat murid mampu menangkap materi pelajaran yang sesuai dengan harapan pembelajaran tersebut.

Sujana dan Rivai (1992:26) mengemukakan penggunaan metode pembelajaran yang efektif dalam proses pembelajaran akan membuat proses belajarmengajar lebih menarik perhatian siswa sehingga dapat memotivasi siswa untuk belajar dan siswa dapat lebih banyak melakukan kegiatan belajar, sebab tidak hanya mendengarkan uraian guru tetapi juga aktifitas lainnya seperti mengamati, melakukan, mendemonstrasikan, memerankan, dan lain-lain.

Berdasarkan hasil pengamatan di lapangan, khususnya di SMA Negeri 1 Cibinong, pembelajaran pada umumnya masih bersifat konvensional. Mursell \& Nasution (2006:11-12), menyatakan bahwa dalam kegiatan belajar mengajar, guru hanya menggunakan metode konvensional seperti menjelaskan materi secara abstrak, hafalan materi dan ceramah. Mereka tidak menyadari apa yang dilakukan tersebut bisa memendam atau menghilangkan potensi-potensi yang dimiliki oleh siswa. Mereka belum menyadari sepenuhnya bahwa dengan menggunakan metode konvensional tersebut hanya ranah kognitif yang dikembangkan sedangkan ranah yang lain (afektif dan psikomotorik) kurang dikembangkan.. Cara pembelajaran konvesional membuat siswa kurang tertarik untuk belajar dan menganggap bahwa pembelajaran bahasa Inggris terasa sulit dan kurang menyenangkan.

Dari penjelasan di atas, maka dapat diketahui bahwa metode pembelajaran memiliki pengaruh yang cukup besar dalam keberhasilan suatu proses belajarmengajar. Salah satu metode yang dapat digunakan dalam pembelajaran keterampilan berbicara bahasa Inggris adalah suggestopedia. Metode ini pertama kali digunakan di Bulgaria dan diciptakan oleh Georgia Lozanov, seorang tokoh pendidikan dari Bulgaria. Prinsip kerja dari metode ini adalah terletak pada sugesti yang mampu menciptakan suasana pembelajaran senyaman mungkin dan mendorong pikiran bawah sadar siswa untuk menciptakan kondisikondisi yang menyenangkan. Tujuan yang paling penting dari suggestopedia adalah untuk memotivasi lebih banyak potensi mental siswa untuk belajar dan yang diperoleh dengan sugesti. Lazanov dikutip dalam Lica (2008) berpendapat bahwa peserta didik memiliki kesulitan dalam memperoleh bahasa Inggris sebagai bahasa kedua, karena para siswa takut jika mereka membuat kesalahan dalam berbicara menggunakan bahasa Inggris. Maka, perlu adanya motivasi dari guru untuk membuat siswa berani berbicara menggunakan bahasa Inggris.

Hal itulah yang mendorong peneliti untuk melakukan penelitian di lapangan dengan fokus yang diteliti, yaitu mencermati variabel metode pembelajaran, kepribadian, dan keterampilan berbicara bahasa Inggris. Oleh karena itu, muncul masalah yang menarik untuk diteliti, yaitu apakah terdapat pengaruh metode pembelajaran dan kepribadian terhadap keterampilan berbicara bahasa Ingrris siswa.

\section{METODOLOGI PENELITIAN}

Penelitian ini menggunakan metode eksperimen dan survey. Penelitian ini dilaksanakan di SMA Negeri 1 Cibinong.

Populasi target pada penelitian ini adalah seluruh siswa SMA Negeri di Cibinong, pada semester ganjil tahun pelajaran 2015/2016. Sedangkan, populasi terjangkau dalam penelitian ini adalah siswa kelas XI SMA Negeri 1 Cibinong pada semester ganjil tahun pelajaran 2015/2016 yang berjumlah 400 orang siswa yang terdapat dalam 9 kelas paralel dengan masingmasing berjumlah 30-40 orang siswa.

Menurut Sudjana (1992:6) "sampel adalah sebagian dari yang diambil populasi”. Selanjutnya Roscoe dalam Sugiyono (2013:74) mengatakan bahwa bila dalam penelitian akan melakukan analisis multivariate, maka jumlah sampel minimal 10 kali jumlah variabel yang akan diteliti (minimal 30 orang sampel). Dalam penelitian ini sampel diambil sebanyak 60 orang siswa yang terbagi atas dua kelompok yaitu 30 orang siswa yang memiliki kepribadian introvert dan 30 orang siswa yang memiliki kepribadian ekstrovert. Peneliti memilih kelas XI IPS 1, XI IPS 2, XI IPS 3, XI IPS 4 sebagai kelompok sampel. 
Penelitian ini menggunakan metode percobaan (experiment) dengan rangcangan atau disain faktorial 2 $\mathrm{x} 2$ sebagai berikut :

Tabel 1. Rancangan Penelitian

\begin{tabular}{cccc}
\hline & \multicolumn{2}{c}{ Metode Pengajaran } & \\
\cline { 2 - 3 } Kepribadian & $\begin{array}{c}\text { Suggestope } \\
\text { dia } \\
\left(\mathrm{A}_{1}\right)\end{array}$ & $\begin{array}{c}\text { Konvensio } \\
\text { nal } \\
\left(\mathrm{A}_{2}\right)\end{array}$ & Total \\
\hline $\begin{array}{c}\text { Ekstrovert } \\
\left(\mathrm{B}_{1}\right)\end{array}$ & $\mathrm{A}_{1} \mathrm{~B}_{1}$ & $\mathrm{~A}_{2} \mathrm{~B}_{1}$ & $\sum \mathrm{B}_{1}$ \\
\hline $\begin{array}{c}\text { Introvert } \\
\left(\mathrm{B}_{2}\right)\end{array}$ & $\mathrm{A}_{1} \mathrm{~B}_{2}$ & $\mathrm{~A}_{2} \mathrm{~B}_{2}$ & $\sum \mathrm{B}_{2}$ \\
\hline TOTAL & $\sum \mathrm{A}_{1}$ & $\sum \mathrm{A}_{2}$ & $\sum$ Total \\
\hline
\end{tabular}

Analisis data dilakukan dalam penelitian ini untuk mengethaui ada atau tidaknya pengaruh metode pembelajaran dan kepribadian terhadap keterampilan berbicara Bahasa Inggris siswa. Data yang dianalisis adalah skor hasil tes masing-masing kelompok dengan ANOVA dua arah.

\section{HASIL DAN PEMBAHASAN}

Dalam bab ini akan dibahas mengenai hasil penelitian yang meliputi deskripsi data, persyaratan analisis, dan uji hipotesis.

\subsection{Deskripsi data}

1. Deskripsi Data Keterampilan Berbicara Bahasa Inggris Kelompok Metode Pembelajaran Suggestopedia (A1)

Data keterampilan berbicara bahasa Inggris yang diperoleh dari para responden kelompok metode pembelajaran suggestopedia mempunyai rata-rata 78,33 dengan simpangan baku 6,343, median sebesar 80,00, skor minimum 65, dan skor maksimum 90. Hal ini menunjukkan bahwa rata-rata keterampilan berbicara bahasa Inggris dari responden termasuk tinggi (karena berada diatas KKM). Jika mempertimbangkan ketuntasan belajar dimana siswa dikatakan tuntas belajar jika nilai yang diperoleh diatas Kriteria Ketuntasan Minimal (KKM) yang telah diterapkan di SMA Negeri 1 Cibinong yaitu 78. Skor simpangan baku 6,343 menunjukkan bahwa pengaruh kemampuan antar responden termasuk tinggi. Hal ini menunjukkan bahwa keterampilan berbicara bahasa Inggris dari responden cukup beragam.

\section{Tabel 2. Deskripsi Statistik Data Keterampilan Berbicara Bahasa Inggris Kelompok Metode Pembelajaran Suggestopedia (A1)}

\section{Statistics}

Metode Pembelajaran Suggestopedia

\begin{tabular}{|c|c|c|}
\hline \multirow[t]{2}{*}{$\mathrm{N}$} & Valid & 30 \\
\hline & Missing & 0 \\
\hline \multicolumn{2}{|c|}{ Mean } & 78,33 \\
\hline \multicolumn{2}{|c|}{ Std. Error of Mean } & 1,158 \\
\hline \multicolumn{2}{|c|}{ Median } & 80,00 \\
\hline \multicolumn{2}{|c|}{ Mode } & 75 \\
\hline \multicolumn{2}{|c|}{ Std. Deviation } & 6,343 \\
\hline \multicolumn{2}{|c|}{ Variance } & 40,230 \\
\hline \multicolumn{2}{|c|}{ Range } & 25 \\
\hline \multicolumn{2}{|c|}{ Minimum } & 65 \\
\hline \multicolumn{2}{|c|}{ Maximum } & 90 \\
\hline
\end{tabular}

2. Deskripsi Data Keterampilan Berbicara Bahasa Inggris Kelompok Metode Pembelajaran Konvensional (A2)

Data keterampilan berbicara bahasa Inggris yang diperoleh dari para responden kelompok metode pembelajaran konvensional mempunyai rata-rata 63,50 dengan simpangan baku 6,715, median sebesar 65,00, skor minimum 50, dan skor maksimum 75 . Hal ini menunjukkan bahwa rata-rata keterampilan berbicara bahasa Inggris dari responden termasuk rendah (karena berada dibawah KKM). Jika mempertimbangkan ketuntasan belajar dimana siswa dikatakan tuntas belajar jika nilai yang diperoleh diatas Kriteria Ketuntasan Minimal (KKM) yang telah diterapkan di SMA Negeri 1 Cibinong yaitu 78. Skor simpangan baku 6,715 menunjukkan bahwa pengaruh kemampuan antar responden termasuk tinggi.

3. Deskripsi Data Keterampilan Berbicara Bahasa Inggris Kelompok Kepribadian Ekstrovert (B1)

Data keterampilan berbicara bahasa Inggris yang diperoleh dari para responden kelompok kepribadian ekstrovert mempunyai rata-rata 79.33 dengan simpangan baku 6.397, median sebesar 80,00, skor minimum 65, dan skor maksimum 90.

4. Deskripsi Data Keterampilan Berbicara Bahasa Inggris Kelompok Kepribadian Introvert (B2) 
Data keterampilan berbicara bahasa Inggris yang diperoleh dari para responden kelompok kepribadian introvert mempunyai rata-rata 69,17 dengan simpangan baku 9.385, median sebesar 70.00, skor minimum 50, dan skor maksimum 85.

\section{B. Persyaratan Analisis}

\section{Uji Normalitas}

Uji normalitas data adalah untuk mengetahui apakah data yang diperoleh terdistribusi normal atau tidak. Dalam penelitian ini pengujian terhadap normalitas data dilakukan dengan menggunakan SPSS.

Berdasarkan tabel One-Sample Kolmogrov-Smirnov Test untuk menguji normalitas variabel terikat dalam hal ini keterampilan berbicara bahasa Inggris siswa. Kriteria jika $>0,05$ pada hipotesis yang menyatakan variable terikat adalah normal bisa diterima. Pada data penelitian menunjukkan sig $=0,068>0.05$ maka data adalah distribusi normal seperti terlihat pada tabel serta terlihat pada lampiran.

Tabel 3. Uji Normalitas Variabel Keterampilan Berbicara Bahasa Inggris Siswa

\section{One-Sample Kolmogorov-Smirnov Test}

Keterampilan

Berbicara

Bahasa Inggris

\begin{tabular}{llr}
\hline $\mathrm{N}$ & & 60 \\
\hline Normal Parameters & a,b & Mean \\
\cline { 2 - 3 } & $\begin{array}{l}\text { Std. } \\
\text { Deviation }\end{array}$ & 70,92 \\
\hline Most Extreme & Absolute &, 110 \\
\cline { 2 - 3 } Differences & Positive &, 108 \\
\cline { 2 - 3 } & Negative &,- 110 \\
\hline Test Statistic & &, 110 \\
\hline Asymp. Sig. (2-tailed) & &, 068
\end{tabular}

a. Test distribution is Normal.

b. Calculated from data.

\section{Uji Homogenitas}

Salah satu syarat yang diperlukan dalam menganalisis data dengan ANOVA adalah uji homogenitas. Tujuan uji homogenitas adalah untuk mengetahui apakah varians populasi bersifat homogenitas atau tidak.

Pengujian homogenitas pada data kelompok sampel dilakukan dengan Levene's pada taraf signifikasi $\alpha=$ 5\%. Adapun ringkasan hasil perhitungan uji homogenitas kelompok sampel terdapat pada tabel dibawah ini:
Tabel 4. Uji Homogenitas Variabel Keterampilan Berbicara Bahasa Inggris

Levene's Test of Equality of Error Variances $^{a}$

Dependent Variable: Keterampilan Berbicara Bahasa Inggris

\begin{tabular}{crrrr}
\hline$F$ & $d f 1$ & & df2 & \multicolumn{1}{r}{ Sig. } \\
\hline 1,631 & & 3 & 56 &, 192 \\
\hline
\end{tabular}

Tests the null hypothesis that the error variance of the dependent variable is equal across groups.

a. Design: Intercept $+A+B+A$ * $B$

Dari perhitungan data di atas dengan SPSS 22 diperoleh nilai sig 0,192 > 0,05 dengan demikian Ho diterima dan $\mathrm{H}_{1}$ ditolak dan data berasal dari populasi homogen. Dari hasil pengujian normalitas dan homogenitas dapat disimpulkan bahwa persyaratan yang harus dipenuhi dalam penelitian ini telah terpenuhi, maka dapat dilanjutkan dengan uji hipotesis penelitian.

\section{Uji Hipotesis}

Pengujian hipotesis penelitian dianalisis menggunakan ANOVA dua arah untuk mengetahui pengaruh dan interaksi antara kelompok. Analisis ANOVA ini menggunakan perhitungan SPSS 22 for windows sebagai berikut:

Tabel 5. Ringkasan Hasil ANOVA Tests of Between-Subjects Effects Dependent Variable: Keterampilan Berbicara Bahasa Inggris

\begin{tabular}{|c|c|c|c|c|c|}
\hline Source & $\begin{array}{l}\text { Type III } \\
\text { Sum of } \\
\text { Squares }\end{array}$ & Df & $\begin{array}{l}\text { Mean } \\
\text { Square }\end{array}$ & $\mathrm{F}$ & Sig. \\
\hline $\begin{array}{l}\text { Corrected } \\
\text { Model }\end{array}$ & $3611,250^{a}$ & 3 & $\begin{array}{r}1203,75 \\
0 \\
\end{array}$ & $\begin{array}{r}31,1 \\
60 \\
\end{array}$ & ,000 \\
\hline Intercept & $\begin{array}{r}301750,41 \\
7 \\
\end{array}$ & 1 & $\begin{array}{r}301750 \\
417 \\
\end{array}$ & $\begin{array}{r}7811 \\
, 105 \\
\end{array}$ & ,000 \\
\hline A & 3300,417 & 1 & $\begin{array}{r}3300,41 \\
7\end{array}$ & $\begin{array}{r}85,4 \\
35\end{array}$ & ,000 \\
\hline B & 260,417 & 1 & 260,417 & $\begin{array}{r}6,74 \\
1 \\
\end{array}$ & ,012 \\
\hline$A * B$ & 50,417 & 1 & 50,417 & $\begin{array}{r}1,30 \\
5\end{array}$ & ,258 \\
\hline Error & 2163,333 & 56 & 38,631 & & \\
\hline Total & $\begin{array}{r}307525,00 \\
0 \\
\end{array}$ & 60 & & & \\
\hline $\begin{array}{l}\text { Corrected } \\
\text { Total }\end{array}$ & 5774,583 & 59 & & & \\
\hline
\end{tabular}




\section{KESIMPULAN}

Merujuk pada hasil pengujian hipotesis penelitian dan analisis pengolahan data pada bab IV, maka dapat disimpulkan sebagai berikut:

1. Terdapat pengaruh metode pembelajaran terhadap keterampilan berbicara bahasa Inggris siswa. Berdasarkan tabel mengenai ringkasan hasil ANOVA di atas, terlihat bahwa $\mathrm{F}_{0}=85,435$ dan sig. $=0,000<0,05$, maka hipotesis nol $\left(\mathrm{H}_{0}\right)$ ditolak dan hipotesis alternatif $\left(\mathrm{H}_{1}\right)$ diterima. Hal ini membuktikan bahwa perbedaan rerata (mean) keterampilan berbicara bahasa Inggris siswa yang diajar dengan menggunakan metode suggestopedia dengan siswa yang diajar dengan metode konvesional adalah berbeda secara signifikan. Siswa yang diajar menggunakan metode suggestopedia $(x A 1=78,33)$ memiliki keterampilan berbicara yang lebih baik dari pada siswa yang diajar dengan metode konvensional $(\mathrm{xA2}=63,50)$.

2. Terdapat pengaruh kepribadian terhadap keterampilan berbicara bahasa Inggris siswa. Berdasarkan tabel mengenai ringkasan hasil ANOVA di atas, terlihat bahwa $\mathrm{F}_{0}=6,741$ dan sig. $=0,012<0,05$, maka hipotesis nol $\left(\mathrm{H}_{0}\right)$ ditolak dan hipotesis alternatif $\left(\mathrm{H}_{1}\right)$ diterima. Hal ini membuktikan bahwa perbedaan rerata (mean) keterampilan berbicara bahasa Inggris siswa yang memiliki kepribadian ekstrovert dengan siswa yang memiliki kepribadia introvert adalah berbeda secara signifikan. Siswa yang memiliki kepribadian ektrovert $(\mathrm{xB1}=73,00)$ memiliki keterampilan berbicara yang lebih baik dari pada siswa yang memiliki kepribadian introvert $(\mathrm{xB2}=$ 68,33). Berdasarkan data tersebut, dapat disimpulkan bahwa terdapat pengaruh yang signifikan kepribadian terhadap keterampilan berbicara bahasa Inggris siswa. Dengan kata lain bahwa terdapat perbedaan hasil belajar siswa yang memiliki kepribadian ekstrovert dengan siswa yang memiliki kepribadian introvert.

3. Tidak terdapat pengaruh interaksi metode pembelajaran dan kepribadian terhadap keterampilan berbicara bahasa Inggris siswa. Berdasarkan tabel mengenai ringkasan hasil ANOVA di atas, terlihat bahwa $\mathrm{F}_{0}=1,305$ dan sig. $=0,258>0,05$, maka hipotesis nol $\left(\mathrm{H}_{0}\right)$ diterima dan hipotesis alternatif $\left(\mathrm{H}_{1}\right)$ ditolak. Hal ini membuktikan bahwa interaksi metode pembelajaran dan kepribadian terhadap keterampilan berbicara bahasa Inggris siwa tidak signifikasn. Adjusted R. Squared sebesar 0,605 berarti variabilitas keterampilan berbicara bahasa
Inggris siswa yang dapat dijelaskan oleh variable metode pembelajaran , kepribadian dan interaksi antara metode pembelajaran dan kepribadian sebesar 60,5\%. Berdasarkan hasil ANOVA, terlihat bahwa interaksi yang terjadi antara metode pembelajaran dan kepribadian pada pelajaran merupakan interaksi yang tidak signifikan. Karena tidak adanya interaksi, maka tidak dilakukan analisis lanjut untuk melihat simple effect diantara sub-sub faktor yang membangun interaksi tersebut.

\section{REFERENSI}

Aiken. 1993. Dinamika Kepribadian. Rineka Cipta. Jakarta.

Allport, Gordon W. 1989. Pengembang Kepribadian. Jakarta : Erlangga.

Alwi, Hasan.2002. Kamus Besar Bahasa Indonesia Edisi Ketiga: Jakarta: Balai Pustaka.

Bailey, K.M., \& Savage, L. 1994. New Ways in Teaching Speaking. Alexandria, VA: Teachers of English to Speakers of Other Languages.

Finocchiaro, Mary. 1997. English as A Second/Foreign Language. New York: Regents Publishing Company.

Gagne, RM \& Briggs, LJ. 1992. Principles of Instructional Design. Fort Worth: Harcourt Brace Jovanovich.

Brown, Gillian and G. Yule. 1983. Discourse Analysis. Cambridge: Cambridge University Press.

Gabriela Mihaila Lica University. 2008. Suggestopedia: A Wonder Approach to Learning Foreign Languages. Assian EFL Journal: English Language Teaching and Research Article. 17 June 20013

$<$ http://www.jaltpublications.org/tlt/files/97/feb/suggest.html>.

Hall, Robert E. 2011. FRIENDS FIRST: An Intuitive Approach to Great Relationships. New York: iUniverse.
Harlock, Elizabeth B. 1998. Psikologi Perkembangan: Suatu Pendekatan Sepanjang Rentang Kehidupan. Jakarta: Erlangga.

Harmer, Jeremy. 1998. How to Teach English. Malaysia: Longman. 
Hasibuan dan Moedjiono. 2006. Proses Belajar Mengajar. Bandung: PT Remaja Rosdakarya.

Horton, Paul B. 1982. Bahasa sebagai Pengembang Kepribadian Manusia. Jakarta : Kompas.

Jung, Carl Gustav. 2001. Volume 11 Key Figures in Counselling and Psychotherapy Series. New York: SAGE.

Kayi, Hayriye. 2006. Teaching Speaking: Activities to Promote Speaking in a Second Language. http://iteslj.org/Articles/Kayi-Teaching Speaking.html

Kumaravadievlu, B. 2006. Understanding Language Teaching From Method to Postmethod. New Jersey: Lawrence Erlbaum Associates Publisher.

Lamm, Robert P and Richard T. Schaefer. 1998. Sociology:Academic Reviewers. Ohio: McGraw-Hill.

Lozanov, G. 1978. Suggestology and Suggestopedia - Theory and Practice. Bulgaria: United Nations Education, Scientific and Cultural Organization.

Madsen, H.S. 1983. Technique in Testing. New York and Oxford. Oxford University Press.

Markin, Rom J. 1974. Consumer Behavior: A Cognitive Orientation. Michigan: McMillan.

Mulyati, Yeti, dkk. 2009. Keterampilan Berbahasa Indonesia SD. Edisi 1. Jakarta: Universitas Terbuka.

Mursell, J. Nasution, S. 2006. Mengajar dengan Sukses. Jakarta : Bumi Aksara.

Nurgiyantoro, Burhan. 1987. Penilaian dalam Pengajaran Bahasa dan Sastra. Yogyakarta: BPFE.

Pervin, Lawrence A. 2003. The Science of Personality. Michigan: Oxford University Press.
Poerwadarminta, W.J.S.2003. Kamus Umum Bahasa Indonesia. Jakarta: Balai Pustaka.

Sudjana dan Rivai. 2002. Media Pendidikan. Jakarta: Balai Pustaka.

Sugiyono. 2006. Statistika Untuk Penelitian, Cetakan Ketujuh. Bandung: CV. Alfabeta.

Stevick, Earl W. 1976. Memory Meaning and Method; Some Psychological Perspectives on Language Learning. Rowley : Newbury House.

Richard, C. Jack. 2008. Teaching Listening and Speaking from Theory to Practice. Cambridge University Press: New York.

Tarigan, Henry Guntur. 1983. Berbicara: Sebagai Suatu Keterampilan Berbahasa. Bandung: Angkasa.

1992. Metode Pengajaran Bahasa. Bandung: Angkasa Bandung.

Team Kurikulum Didaktik Metodik Kurikulum IKIP Surabaya. 1993. Pengantar Didaktik Metodik Kurikulum PBM. Surabaya: IKIP.

Zuriah, Nurul. 2006. Metodologi Penelitian Sosial dan Pendidikan. Jakarta: Bumi Aksara.

\section{PROFIL PENULIS}

Rizky Mirani Desi Pratama, SS, M.Pd was born in Cilacap, 10 December 1989. She graduated from STIBA Nusa Mandiri Tangerang majoring literature and post graduate program from Indraprasta PGRI university at Department of Language Education. She has been teaching for almost 5 years in Academy of foreign language Bina Sarana Informatika Jakarta (ABA BSI). 